\title{
DEVELOPING AN OPTIMAL METHOD FOR THE ROOTING AND SEEDLING GROWTH OF MEDICINAL SPECIES BUDDLEJA POLYSTACHYA FRESEN: A STEP TOWARDS MASS PRODUCTION
}

\author{
AhMED, A. I. ${ }^{*}$ - AREF, I. M. - AL-MEFARREJ, H. A. \\ Department of Plant Production, College of Food and Agricultural Sciences, King Saud \\ University, Riyadh, Saudi Arabia \\ (e-mail/phone: iaref@ksu.edu.sa/+966-551-331-110; mefarrej@ksu.edu.sa/+966-114-697-193) \\ *Corresponding author \\ e-mail: abahmed@ksu.edu.sa; phone: +966-500-466-537; ORCID: 0000-0001-9074-8474
}

(Received $4^{\text {th }}$ Jun 2020; accepted $16^{\text {th }}$ Sep 2020)

\begin{abstract}
For the improving regeneration and conservation of medicinal B. polystachya, stem cuttings were obtained from trees in Aseer area, Saudi Arabia, and two experiments were conducted to investigate factors affecting rooting (season and auxin type and concentration) and assessing growth performance of rooted cuttings. To test rooting factors, cuttings were collected during autumn, winter, and spring and treated with 500, 1000, and $2000 \mathrm{ppm}$ indole-3-acetic acid (IAA), indole-3-butyric acid (IBA), and naphthyl acetic acid (NAA) during each season. Following the evaluation of rooting, the second experiment was conducted using the best rooted cuttings, to test growth performance of seedlings under the effect of different auxins and four types of growth media. Cuttings collected during spring and treated with IBA had the highest rooting percentage (91\%-98\%), number of roots (23-29 roots cutting ${ }^{-1}$ ), and root length (26-39 cm). Regarding seedling growth, planting cuttings in growth substrate containing clay, sand, and peat moss $(1: 1: 1 \mathrm{v} / \mathrm{v})$ resulted in highest quality seedlings in terms of leaf number, stem height and relative growth rate. We concluded that spring cuttings collection treatment with $1000 \mathrm{ppm} \mathrm{IBA}$, and transplantation to fertile growth media can be a useful technique for mass production of $B$. polystachya

Keywords: propagation, auxins, cuttings, growth media, season
\end{abstract}

\section{Introduction}

The development of vegetative propagation methods is a useful tool for the conservation of genetic resources, domestication of tree species, and national and international forest conservation plans. Hence, vegetative techniques are used as an essential tool for the mass multiplication of superior phenotypes/genotypes and production of true to type uniform plants (Thakur et al., 2008). Rooting of stem cuttings is a simple and economically feasible method of vegetative propagation usually utilized for many tree species (Mewar and Naithani, 2016). Several factors affect rooting such as the mother plant age, season, and application of root exogenous promoting hormones. Therefore, it is essential to understand the critical factors influencing rooting (Shekhawat and Manokari, 2016; Siddiqui and Hussain, 2007).

Roots development of cuttings differs from species to species. A variety of pretreatments are performed to facilitate the successful rooting of cuttings such as, application of auxins which is the most common pretreatment in the vegetative propagation of plants. Many studies suggested that auxins a play detrimental role in rooting capacity by facilitating the earlier production of rooted cuttings that will necessary for vegetative propagation (Fogaca and Fett-Neto, 2005; Topacoglu et al., 2016). Adekola and Akpan (2012) and Sardoei et al. (2013) concluded that these auxins 
included indole-3-acetic acid (IAA), indole-3-butyric acid (IBA), and naphthyl acetic acid (NAA). The rooting period of plants following auxin application varies from species to species. In addition to other factors, auxins play a vital role in controlling plant growth and development influence the production of primary, secondary, and adventitious roots; they are the most frequently used plant growth hormones for rooting of cuttings in nursery practice. The commonly used auxin is IBA is synthetic auxin commonly used as an effective hormone to promote adventitious roots initiation compared to natural IAA (Pop et al., 2011). Successful propagation with the use of cuttings needs to select the right time cuttings collection, and this is intimately related to the natural phytohormones contents (Cristofori et al., 2010). In general, the growth medium is the most important factor determining seedling quality in the nursery (Baiyerin and Mbah, 2006).

Buddleja is a genus of flowering plants comprising approximately 100 species native to the tropics in America, Asia, and Africa (Corte's et al., 2006; El-Sayed et al., 2008). B. polystachya Fresen. is a multi-branched shrub that grow up to five meters; however, it may irregularly reached twelve meters height under favorable environment. This tree is widespread in the semi-arid highlands near the Red Sea coastal and distributed naturally in some countries like Eritrea, Ethiopia, Saudi Arabia, and Yemen where grown around forest, usually beside watercourse, at elevations 2200-3600 m above sea level (Chaudhary, 2001; Mohamedkassm et al., 2013). Several Buddleja species have been used in traditional medicine in many parts of the world, and the roots, leaves, and flowers of various Buddleja species have been used in folk medicine (Corte's et al., 2006; El-Sayed et al., 2008; Mohammed et al., 2016) reported that crude extracts of $B$. polystachya leaves contain certain chemical constituents that could possibly lead to antimalarial drug development and further more Al Ati et al. (2015) isolated and evaluated fifteen compounds from B. polystachya growing wild in Asir, one of these compound ethyl acetate fraction showed the most significant anti-inflammatory activity. Unfortunately, this valuable species is now present in a list of seriously endangered species according to International Union for Conservation of Nature and Natural Resources (IUCN, 2016).

This research work represented step to develop efficient and easy methods for the rehabilitation and conservation of $B$. polystachya, an ecologically and medicinally valuable species, by identifying the appropriate season for collection of cuttings and determining the types and concentrations of auxins for vegetative propagation and factors improving seedling growth such as growth media and auxin types.

\section{Material and methods}

\section{First experiment}

Site and seasons of cuttings collection: Healthy and uniform woody stem cuttings (average length $15 \pm 3.5 \mathrm{~cm}$ ) were collected during specific months of each season, autumn (September), winter (December), and spring (March), from stock trees of $B$. polystachya growing wild as scattered trees among others tree species in the Aseer region $\left(18^{\circ} 12^{\prime} 63^{\prime \prime} \mathrm{N}, 42^{\circ} 31^{\prime} 01^{\prime \prime} \mathrm{E}\right.$; $2093.4 \mathrm{~m}$ above sea level), in the southwest of Saudi Arabia. This region is characterized by an average annual rainfall of $373.4 \mathrm{~mm}$; monthly mean, minimum, and maximum temperature of $19.2{ }^{\circ} \mathrm{C}, 7.56{ }^{\circ} \mathrm{C}$, and $31.0{ }^{\circ} \mathrm{C}$, respectively; and relative humidity between $14.5 \%$ to $91.6 \%$. All stem cuttings were collected in the early dawn (07:00 am) and kept in a plastic sealed ice container to 
minimize drying. This experiment was designed to test the interaction effects of auxin type, their concentrations, and season of collecting cuttings on vegetative propagation of B. polystachya using stem cuttings. This experiment was repeated thrice during autumn, winter, and spring.

\section{Experimental site}

The study was conducted in a greenhouse at the College of Food and Agricultural Science, King Saud University, Saudi Arabia under controlled temperature $\left(25 \pm 1{ }^{\circ} \mathrm{C}\right)$ conditions with $12 / 12 \mathrm{~h}$ of light/darkness, and irrigated whenever needed during the period of the experiment. The vegetative propagation unit inside the greenhouse was covered using transparent plastic and equipped with a mist device.

\section{Description and application of treatments}

Three phases of the first experiment were conducted using three auxin types and concentrations, during autumn (September, October and November 2017), winter (December 2017, January and February 2018), and spring (March, April and May 2018) in order to test major factors affecting rooting ability of this species. Thirty treatments were applied, comprising three growth auxins, three concentrations of each auxin, and three seasons of cuttings collection ( 3 auxins $\times 3$ concentrations $\times 3$ seasons +3 controls) (Table 1). The plant growth auxins (IAA, IBA, and NAA) were imported from Sigma. Stock solutions of the three auxins were prepared at concentrations of 500,1000, and $2000 \mathrm{ppm}$ by weighing the respective fresh weight (g) of each auxin and dissolving in distilled water. Cuttings were immersed in each auxin concentration for 5 min before planting in nursery beds $(3 \times 0.5 \times 2 \mathrm{~m})$ with sand rooting media and cuttings were inserted 5-6 $\mathrm{cm}$ deep using a wooden stick.

\section{Measurements}

After 12 weeks, the assessment of rooting success was performed by harvesting five replicates from each treatment to evaluate the root formation of stem cuttings collected for the period of the first collection season (autumn) by manually counting the number of rooted cuttings (for rooting percentage computation) and number of roots per cutting, whereas root length was measured from the point of emergence to the tip using a linear meter. The evaluation of rooting was performed in the same way for the remaining two seasons (winter and spring).

\section{Second experiment}

Following screening for the factors improving rooting from the results of the first experiment, the second experiment was performed to test the effect of auxin type and seedling growth media on the growth of seedlings. Results of the first experiment showed approximately higher rooting percentage, number of roots and root length occurring in cuttings treated with $1000 \mathrm{ppm}$ of the three auxins and collected during spring than in those of the other treatments and seasons. Therefore, three replicates of cuttings from each treatment of $1000 \mathrm{ppm}$ of IAA, IBA, and NAA were transplanted into four growth media (clay, sand, combination of clay + sand $(1: 1 \mathrm{v} / \mathrm{v})$, and clay + sand + peat moss $(1: 1: 1 \mathrm{v} / \mathrm{v})$. Table 2 showed the growth media properties, such as soil organic carbon percentage (OC \%) was obtained as described by Nelson and 


$$
-7396-
$$

Sommers (1982), soil texture was determined using the micropipette method (Miller and Miller, 1987), and water-holding capacity of soil was determined by the pressure plate method as described by Topp et al. (1993). After 12 weeks, for the evaluation of seedling growth, number of leaves per cutting were counted manually and relative growth rate of seedling height $\mathrm{RGR}(\mathrm{H})$ was estimated according to Equationl (Ostos et al., 2008).

$$
\mathrm{RGR}(\mathrm{H})=(\mathrm{LnH} 2-\mathrm{LnH} 1) / \mathrm{t} 2-\mathrm{t} 1
$$

where: $\operatorname{RGR}(\mathrm{H})=$ seedling height relative growth rate; $\mathrm{H} 1$ and $\mathrm{H} 2=$ initial and final seedling height, respectively; $\mathrm{t} 2$ and $\mathrm{t} 1=$ initial time and final time in month respectively.

\begin{tabular}{|c|c|c|c|}
\hline \multirow[b]{2}{*}{ Treatments } & \multicolumn{3}{|c|}{ Treatment description } \\
\hline & Auxin & $\begin{array}{c}\text { Auxin concentration } \\
(\mathbf{p p m})\end{array}$ & Season \\
\hline IAA $* 500 *$ Autumn & IAA & 500 & Autumn \\
\hline IAA $* 500 *$ Winter & IAA & 500 & Winter \\
\hline IAA $* 500 *$ Spring & IAA & 500 & Summer \\
\hline IAA*1000* Autumn & IAA & 1000 & Autumn \\
\hline IAA $* 1000 *$ Winter & IAA & 1000 & Winter \\
\hline IAA*1000*Spring & IAA & 1000 & Summer \\
\hline IAA $* 2000 *$ Autumn & IAA & 2000 & Autumn \\
\hline IAA $* 2000 *$ Winter & IAA & 2000 & Winter \\
\hline IAA $* 2000 *$ Spring & IAA & 2000 & Summer \\
\hline IBA $* 500 *$ Autumn & IBA & 500 & Autumn \\
\hline IBA $* 500 *$ Winter & IBA & 500 & Winter \\
\hline IBA $* 500 *$ Spring & IBA & 500 & Summer \\
\hline IBA* $1000 *$ Autumn & IBA & 1000 & Autumn \\
\hline IBA*1000*Winter & IBA & 1000 & Winter \\
\hline IBA*1000*Spring & IBA & 1000 & Summer \\
\hline IBA*2000*Autumn & IBA & 2000 & Autumn \\
\hline IBA*2000*Winter & IBA & 2000 & Winter \\
\hline IBA $* 2000 *$ Spring & IBA & 2000 & Summer \\
\hline NAA*500*Autumn & NAA & 500 & Autumn \\
\hline NAA $* 500 *$ Winter & NAA & 500 & Winter \\
\hline NAA*500*Spring & NAA & 500 & Summer \\
\hline NAA*1000*Autumn & NAA & 1000 & Autumn \\
\hline NAA*1000*Winter & NAA & 1000 & Winter \\
\hline NAA*1000*Spring & NAA & 1000 & Summer \\
\hline NAA $* 2000 *$ Autumn & $\mathrm{NAA}$ & 2000 & Autumn \\
\hline NAA $* 2000 *$ Winter & NAA & 2000 & Winter \\
\hline NAA $* 2000 *$ Spring & NAA & 2000 & Summer \\
\hline DW*0*Autumn & Distilled water & 0 & Autumn \\
\hline $\mathrm{DW} * 0 *$ Winter & Distilled water & 0 & Winter \\
\hline DW*0*Spring & Distilled water & 0 & Summer \\
\hline
\end{tabular}

Table 1. Treatment descriptions 
Table 2. Growth media properties

\begin{tabular}{c|c|c|c}
\hline \multirow{2}{*}{ Growth media } & \multicolumn{3}{|c}{ Property } \\
\cline { 2 - 4 } & Grain size $(\mathbf{m m})$ & WHC $(\mathbf{m m} / \mathbf{m} 2)$ & OC $(\boldsymbol{\%})$ \\
\hline Sand & $0.1-2.0$ & $60-113$ & 0.10 \\
Clay & $<0.01$ & $122-195$ & 1.20 \\
Sand + Clay (1:1) & $0.075-0.10$ & $106-148$ & 1.32 \\
Sand + clay + peat moss (1:1:1) & $0.90-0.14$ & $125-181$ & 20.50 \\
\hline
\end{tabular}

\section{Experimental design}

For the first experiment a factorial experiment $(3 \times 3 \times 3)$ was set up using three different factors (three plant growth auxins, three concentrations of each auxin, and three seasons of cutting collection). The experiment was laid out in a completely randomized manner with five replicates per treatment. Then, the second experiment was designed as a factorial $(3 \times 4)$ of three auxins and four growth media.

\section{Statistical analysis}

The following statistical analyses were used: ANOVA was used to test the effect of treatments, the least significant difference multiple range-tests were used to identify differences between means, and the general linear model was used to test the interaction between the three tested factors (auxins, concentrations, and seasons of collecting cuttings). All statistical analyses were achieved by using SAS version 9.3.

\section{Results}

\section{Rooting percentage}

The interaction of auxin types, auxin concentrations, and time of collection of cuttings had highly significant $(\mathrm{p}<0.05)$ effects on rooting percentage. All cuttings treated with the different concentrations of auxins showed a high mean rooting percentage $(72 \%)$ regardless of collection season. However, although there is no significant difference between means of 1000, 2000 and 500 ppm IBA treatments, but the highest rooting percentages $(98,95 \%$ and $91 \%)$ were obtained in cuttings collected in spring when treated with the three levels of IBA (1000, 2000 and $500 \mathrm{ppm}$ receptively), followed by cuttings treated with $2000 \mathrm{ppm}$ of IAA and NAA (89.5\%, and 86.4\%) The minimum rooting percentages $(59 \%, 63 \%$, and $65 \%)$ were obtained in the control cuttings collected during the three season's autumn, winter and spring, respectively (Fig. 1.)

\section{Number of roots per cutting}

The interaction among auxin types, auxin concentrations, and collection season of cuttings on number of roots per cutting was highly significant. However, the combination of IBA, its concentration, and collection season resulted in differences in the mean number of roots per cutting, and cuttings collected during spring and treated with 500 or 1000 ppm of IBA, had the maximum roots per cutting (28.6 and 26.4 roots, respectively), followed by treatment with 2000 ppm IAA (24.6 roots) in comparison to the other treatments. In contrast, the minimum number of roots per cutting (1.0-2.8 roots) was recorded in the control cuttings during all seasons (Fig. 2). 


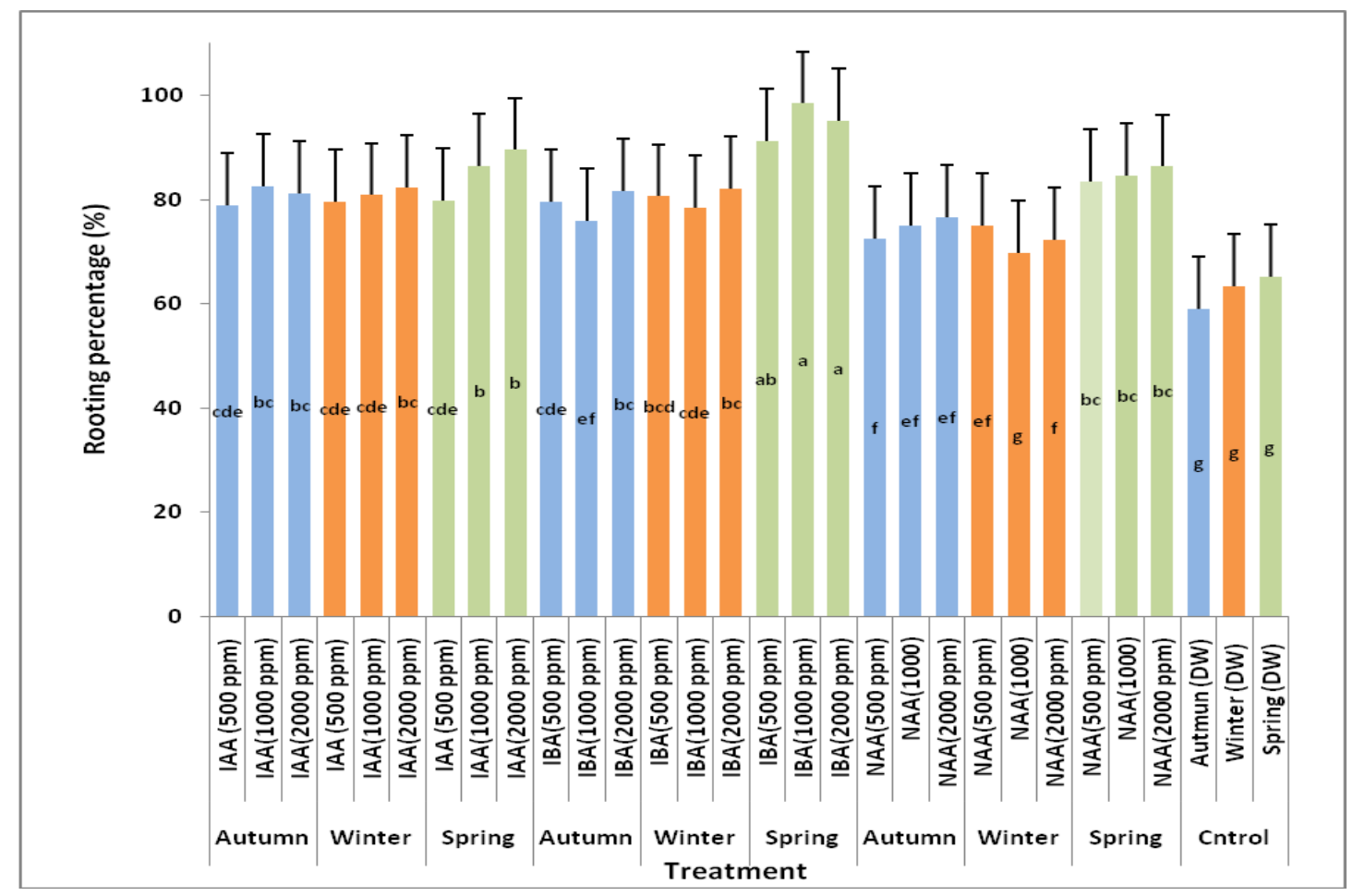

Figure 1. Effect of treatments (three concentrations of IAA, IBA, and NAA and three seasons of cuttings collection) on rooting percentage of B. polystachya after 120 days. Columns with different letters indicate least significant differences $(P<0.05) . D W=$ Distilled water

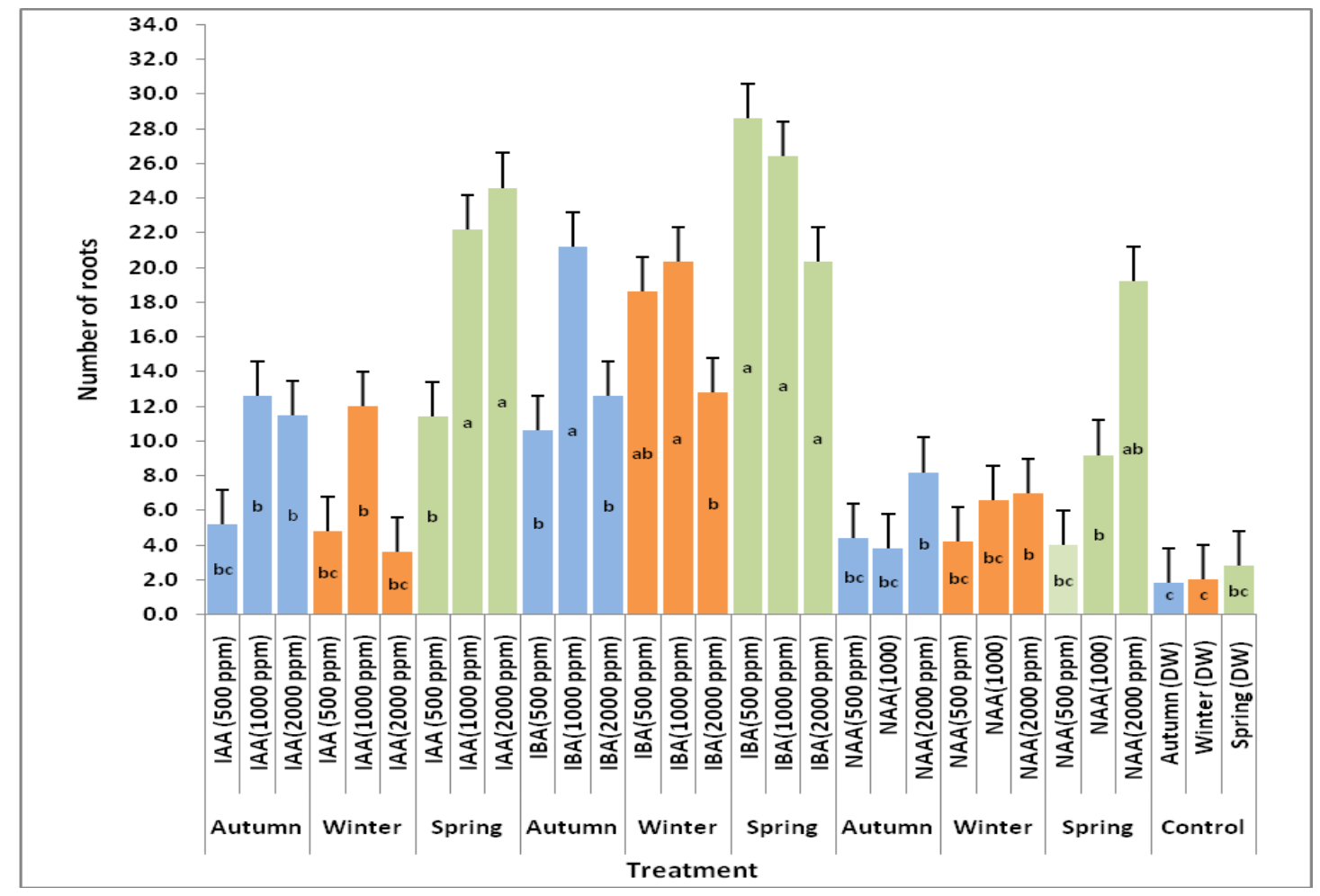

Figure 2. Effect of treatments (three concentrations of IAA, IBA, and NAA and three seasons of cuttings collection) on number of roots per cutting of B. polystachya after 120 days. Columns with different letters indicate least significant differences $(P<0.05) . D W=$ Distilled water 


$$
-7399 \text { - }
$$

\section{Root length (cm)}

The interaction effects of factors significantly improved root length in cuttings. The longest roots were $39.8,27.5,26.3$, and $24.9 \mathrm{~cm}$, recorded in cuttings collected during spring and treated with 500, 1000, and $2000 \mathrm{ppm}$ of IBA and $2000 \mathrm{ppm}$ of IAA, respectively. In addition, some cuttings collected during autumn had longer roots, especially under treatments with 1000 and 2000 ppm IBA. All control cuttings had the least root lengths (Fig. 3).

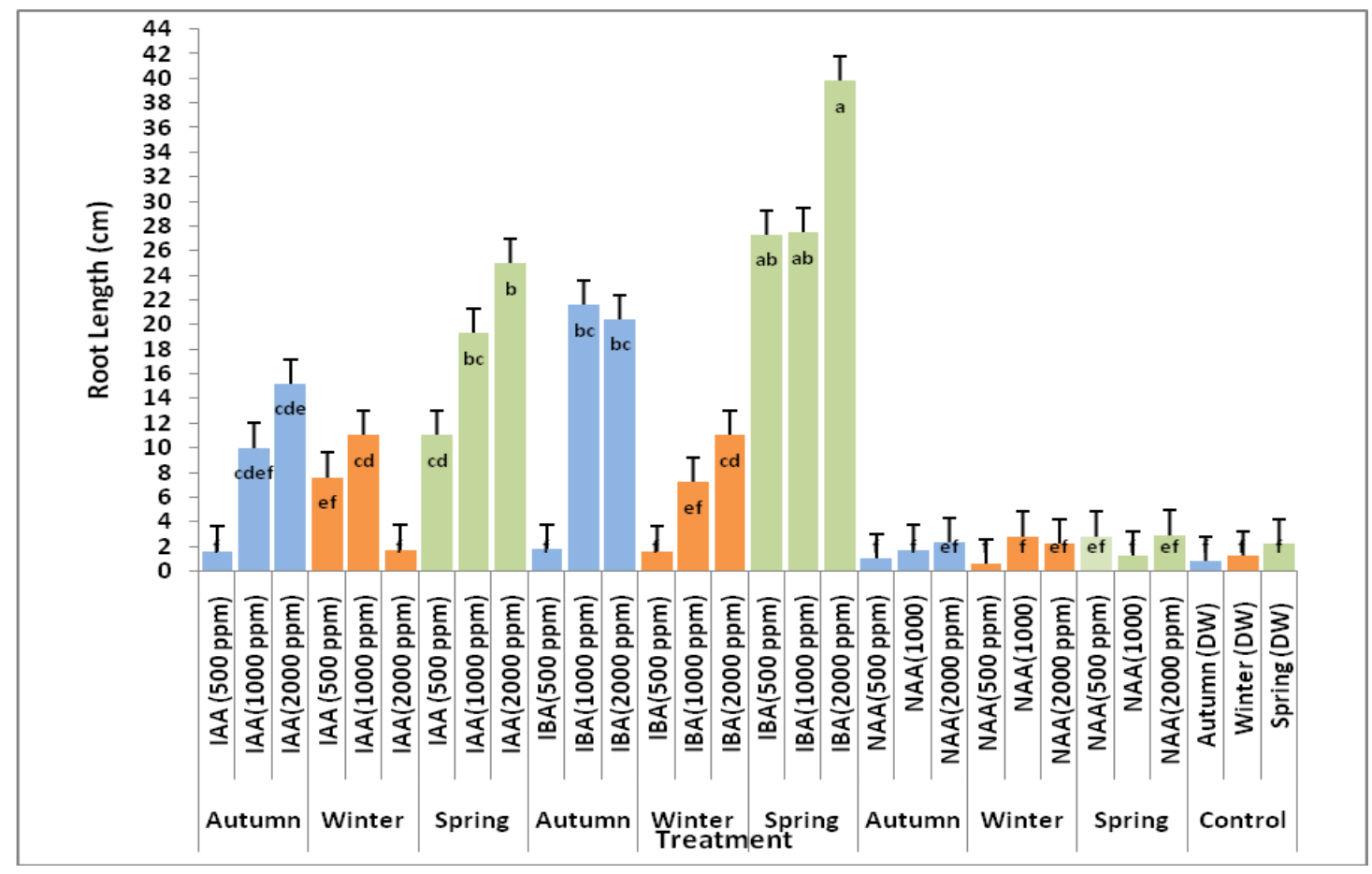

Figure 3. Effect of treatment (three concentrations of IAA, IBA, and NAA and three seasons of cuttings collection) on root length of B. polystachya after 120 days. Columns with different letters indicate least significant differences $(P<0.05) . D W=$ Distilled water

\section{Factors enhancing seedlings growth}

Type of auxins and growth media significantly increased leaves per seedling. However, cuttings treated with IAA, IBA, and NAA grown in a mixture comprising peat moss with clay and sand $(1: 1: 1 \mathrm{v} / \mathrm{v})$ had the highest number of leaves (number of leaves increased by 144,135 , and $130 \%$, respectively) compared to that in the control cuttings grown in the same media. In addition, cuttings treated with IBA grown in clay + sand $(1: 1 \mathrm{v} / \mathrm{v})$ had a higher percentage $(115 \%)$ of number of leaves per cutting than the control seedlings grown in the same media. $\mathrm{RGR}(\mathrm{H})$ had the same trend as number of leaves per seedling, i.e., seedlings grown in media comprising a mixture of clay, sand, and peat moss had the highest rate of growth, followed by those grown in clay + sand media (Table 3).

\section{Discussion}

This study found that vegetative propagation of $B$. polystachya is considerably easy with the use of stem cuttings. However, for mass vegetative propagation aimed at 
obtaining a higher rooting percentage and vigorous seedlings with the highest number of long roots within the shortest time, the best time for collection of cuttings is spring and 1000 ppm IBA and 2000 ppm IAA and NAA are the best concentrations for treatment with auxins. The vegetative propagation of $B$. polystachya from stem cuttings is to some extent easy with or without the application of auxins, but cuttings treated with auxins had significantly higher number of roots and root length, especially the treatment with IBA. All three auxins promoted adventitious roots formation in the stem cuttings (Fig. 4), which is necessary for the vegetative propagation of many plant species (Druege et al., 2019). Auxins or plant growth hormones were used effectively in many plant species to promote the rooting of cuttings (Soundy et al., 2008; Singh et al., 2011; Sağlam et al., 2014).

Table 3. Interaction effect of Auxin and growth media on leaves per cutting and $R G R(H)$

\begin{tabular}{|c|c|c|}
\hline Treatment & Leaves per seedling & $\operatorname{RGR}(\mathrm{H})\left(\mathrm{cm} \mathrm{cm}^{-2}\right.$ month $\left.^{-1}\right)$ \\
\hline IAA*clay & $14.85 \pm 1.30^{b c}$ & $0.395 \pm 0.035 \mathrm{bc}$ \\
\hline IAA*sand & $18.67 \pm 2.01^{b}$ & $0.624 \pm 0.015^{\mathrm{ab}}$ \\
\hline IAA*clay-sand $(1: 1 \mathrm{v} / \mathrm{v})$ & $11.94 \pm 0.96 \mathrm{dc}$ & $0.177 \pm 0.011^{\mathrm{cd}}$ \\
\hline IAA $*$ clay + sand + peat moss $(1: 1: 1 \mathrm{v} / \mathrm{v})$ & $28.41 \pm 3.41^{\mathrm{a}}$ & $1.044 \pm 0.118^{\mathrm{a}}$ \\
\hline $\mathrm{IBA}^{*}$ clay & $15.66 \pm 2.07 \mathrm{bc}$ & $0.449 \pm 0.084$ bc \\
\hline IBA*sand & $15.66 \pm 1.93 \mathrm{bc}$ & $0.468 \pm 0.074 \mathrm{bc}$ \\
\hline IBA*clay-sand $(1: 1 \mathrm{v} / \mathrm{v})$ & $25.10 \pm 3.05^{\mathrm{ab}}$ & $0.9200 .070^{\mathrm{ab}}$ \\
\hline IBA*clay + sand + peat moss $(1: 1: 1 \mathrm{v} / \mathrm{v})$ & $27.36 \pm 2.65^{\mathrm{ab}}$ & $0.982 \pm 0.03$ ab \\
\hline NAA*clay & $14.47 \pm 1.98^{\mathrm{cd}}$ & $0.369 \pm 0.002^{b c}$ \\
\hline $\mathrm{NAA}^{*}$ sand & $17.25 \pm 2.11 \mathrm{bc}$ & $0.545 \pm 0.012^{b c}$ \\
\hline NAA*clay-sand $(1: 1)$ & $13.00 \pm 1.74^{\mathrm{bc}}$ & $0.262 \pm 0.004$ bc \\
\hline $\mathrm{NAA} *$ clay + sand + peat moss $(1: 1: 1 \mathrm{v} / \mathrm{v} /$ & $26.70 \pm 3.07 \mathrm{ab}$ & $1.006 \pm 0.027^{\mathrm{a}}$ \\
\hline $\mathrm{DW}^{*}$ clay & $10.50 \pm 2.50^{\mathrm{cd}}$ & $0.049 \pm 0.002^{\mathrm{d}}$ \\
\hline $\mathrm{DW}^{*}$ sand & $10.96 \pm 3.22^{\mathrm{cd}}$ & $0.092 \pm 0.041^{\mathrm{d}}$ \\
\hline DW*clay-sand $(1: 1 \mathrm{v} / \mathrm{v})$ & $11.63 \pm 1.87^{\mathrm{cd}}$ & $0.151 \pm 0.023^{\mathrm{cd}}$ \\
\hline $\mathrm{DW} *$ clay + sand + peat moss $(1: 1: 1 \mathrm{v} / \mathrm{v})$ & $11.63 \pm 1.74^{\mathrm{cd}}$ & $0.163 \pm 0.024^{\mathrm{cd}}$ \\
\hline Level of significant ( $\mathrm{p}$-value) & $<0.0141$ & $<0.0001$ \\
\hline
\end{tabular}

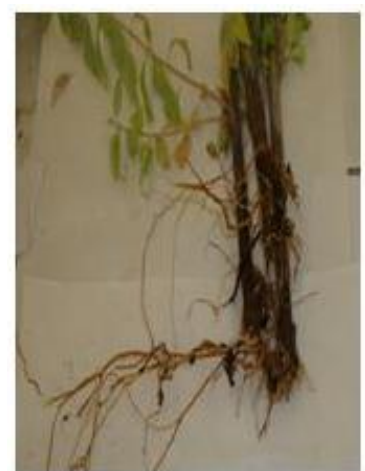

$\mathbf{a}$

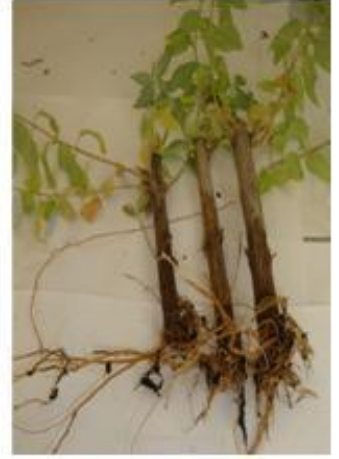

b

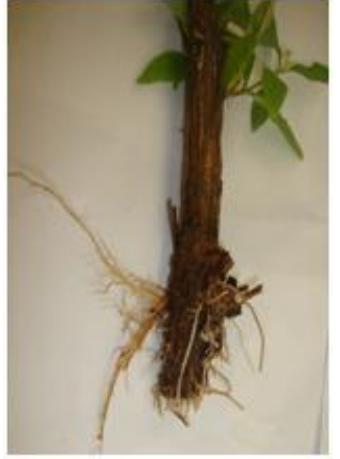

c

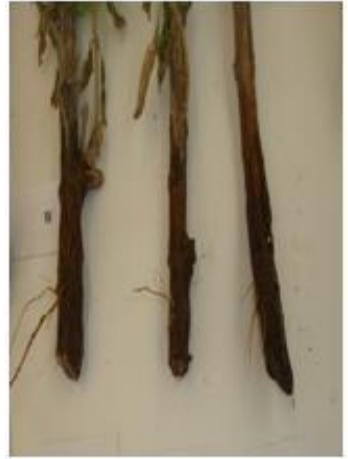

d

Figure 4. Root density of stem cuttings collected during spring and treated with 1000 ppm of $(a)$ $I A A,(b) I B A,(c) N A A$ and (d) control 
Various studies investigated the effects of different auxins on vegetative propagation via cuttings rooting and plant growth. Sevik and Guney (2013) study the effects of IAA, IBA, NAA, and gibberallic acid (GA3) in Melissa officinalis; Stefancic et al. (2005) investigated the effects of IAA and IBA in Prunus spp.; and Chhun et al. (2003) study the effects of IAA, IBA, and NAA in Oryza sativa. These studies generally confirmed that the auxins or hormones have a significant effect on rooting, and consistent with these findings, the present study confirms that auxins can be a useful substance for increasing rooting in cuttings (Salmi and Hesami, 2016). The results revealed that increasing the level of the IAA, IBA, and NAA enhanced rooting percentage, number of roots per cutting, and root length. The role of increasing levels of auxin is well documented. An increased auxin concentration in the stem cutting produced by active auxin transferred from the leaves activated adventitious root creation from the cambium (Justamante et al., 2019). We found that the appropriate time for B. polystachya cuttings collection is spring, and our results further confirmed that the season of cuttings collection is a critical factor for successful rooting. Our results confirmed the findings of other studies, the time of cuttings collection to be a major factor influence propagation of plant (Klein et al., 2000; Swamy et al., 2002; Haile et al., 2011). Ling and Zhong (2012) reported enhancing in rooting percentage of the Tetraploid Locust during May. Seasonal differences in successful rooting are common in woody plants, and the optimal season for rooting must be established independently for each species (Hussain et al., 2014). The rooting medium considered as proper atmosphere for rooting of cuttings (Tchinda et al., 2013), we used sand as the rooting medium in the first experiment, following Adugna et al. (2015) who used fine sand as rooting medium for $V$. planifolia stem cuttings and obtained $99.3 \%$ percentage of rooting. Although all seedlings were treated with the same concentrations of auxins and collected in the same season (spring), the interaction between IBA and combination of clay, sand, and peat moss was found to be more effective compared to that of the other two auxins and media (Table 3 and Fig. 5).

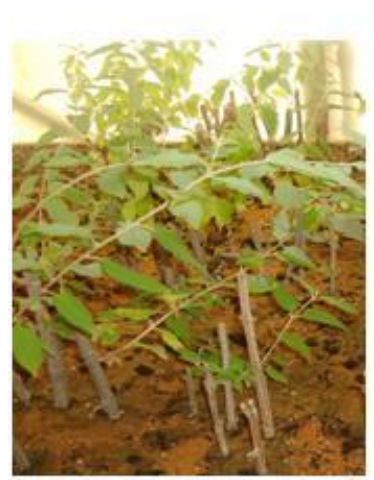

$\mathbf{a}$

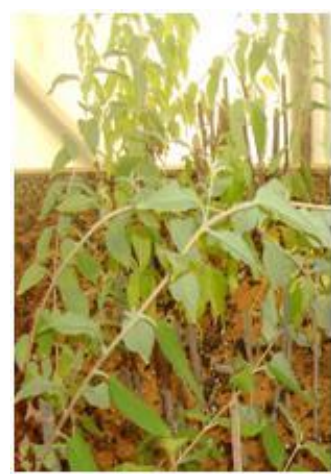

b

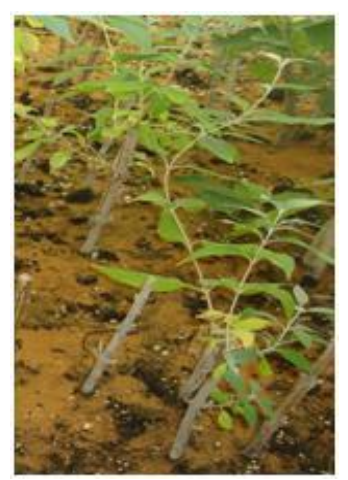

c

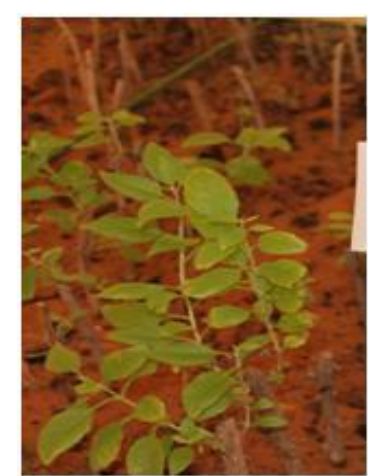

d

Figure 5. Growth performance of seedlings under the effect of media (clay, sand, and peat moss $(1: 1: 1 \mathrm{v} / \mathrm{v})$ treated with $1000 \mathrm{ppm}$ of (a) IAA, (b) IBA, (c) NAA, and (d) control

The combination of clay, sand, and peat moss was the best growth medium in comparison to the other media. This interaction enhanced seedling growth in terms of increasing number of leaves and RGR(H). This can be due to the higher content of organic matter and water holding capacity of the medium. These results are previously conformed by findings of by Neelam et al. (2001) who reported that media with improved soil physical 
and chemical traits and aeration leaded to superior plant growth and consistence with previously findings of Ahmed et al. (2017) who reported that media consisting of clay, sand and peat moss in equal ratios enhanced seedlings growth of $B$. aegyptiaca. Furthermore, there are several studies indicating the effect of organic matter on soil fertility (Martinez et al., 2003), survival and growth (Larchevêque et al., 2006), biomass (Moreno-Peñaranda et al., 2004), and seedling quality (Mañas et al., 2009).

\section{Conclusions}

This study developed an optimal method for the vegetative propagation of $B$. polystachya via woody stem cuttings. The results confirm that woody stem cuttings collected during the spring season and treated with 1000 ppm of IBA or 2000 ppm IAA or NAA had a high rooting percentage with high quality rooted cuttings, i.e., dense and longer roots. Rooted cuttings planted in a combination of clay, sand, and peat moss in equal proportion had dense, long roots. However, in general, seedlings resulting from stem cuttings treated with IBA were superior to seedlings from the other treatments in terms of shoot development (the highest number of leaves and stem height relative to the growth rate) after 6 months. Rooting of stem cuttings of $B$. polystachya is a feasible propagation method for producing high quality seedlings, which can be used as an adequate stock for rehabilitation, conservation, and future studies on the medicinal properties of this valuable tree species. Further research work should be needed to investigate mass propagation of this species using other methods of propagation as micro- propagation or crafting. More research will be needed to evaluate growth performance and or success of seedlings resulting from vegetative propagation under field or nursery conditions.

Acknowledgments. The authors would like to extend their sincere appreciation to the Deanship of Scientific Research at the King Saud University for its funding of this research through the Research Group Project No. RGP-VPP-226.

\section{REFERENCES}

[1] Adekola, O. F., Akpan, I. G. (2012): Effect of growth hormones on sprouting and rooting of Jatropha curcas L. stem cuttings. - Journal of Applied Sciences and Environmental Management 16: 153-156.

[2] Adugna, M., Belew, D., Tilahun, D. (2015): Influence of rooting media and number of nodes per stem cuttings on nursery performance of vanilla (Vanilla planifolia Andr. syn Vanilla fragrans). - Journal of Horticulture and Forestry 7: 48-56.

[3] Ahmed, A. I., Aref, I. M., El-Atta, H. A., Iqbal, M. (2017): Enhancing propagation and Growth of Balanites aegyptiaca through seed pretreatment. - Journal of Environmental Biology 38: 617-622.

[4] Al Ati, H. Y., Fawzy, G. A., Gamal, A. A., Khalil, A. T., El Tahir, K. E., Abdel-Kader, M. S., Gilani, A. (2015): Phytochemical and biological evaluation of Buddleja polystachya growing in Saudi Arabia. - Pakistan Journal of Pharmaceutical Sciences 28(4): 1533-1540.

[5] Baiyerin, K. P., Mbah, B. N. (2006): Effects of soilless and soil based nursery media on seedling emergence, growth and response to water stress of African bread fruit (Treculia africana Decne). - African Journal of Biotechnology 5: 1405-1410. 


$$
-7403-
$$

[6] Chaudhary, S. A. (2001): Flora of the Kingdom of Saudi Arabia. Part 2, Vol. 2: 1-4. Ministry of Agriculture and Water, National Agriculture Research Centre, Riyadh.

[7] Chhun, T., Taketa, S., Tsurumi, S., Ichii, M. (2003): The effects of auxin on lateral root initiation and root gravitropism in a lateral rootless mutant Lrt1 of rice (Oryza sativa $\mathrm{L}$ ). Plant Growth Regulation 39: 161-170.

[8] Corte's, A. R., Delgadillo, A. J., Hurtado, M., Dominguez, A. M., Medina, J. R. (2006): The antispasmodic activity of Buddleja scordioides and Buddleja perfoliata on isolated intestinal preparations. - Biological and Pharmaceutical Bulletin 9: 1186-1190.

[9] Cristofori, V., Rouphael, Y., Rugini, E. (2010): Collection time, cutting age, IBA and putrescine effects on root formation in Corylus avellana L cuttings. - Scientia Horticulturae 124: 189-194.

[10] Druege, U., Hilo, A., Pérez-Pérez, J. M., Koplotek, Y., Acosta, M., Shahinnia, F., Zerche, S., Franken, P., Hajirezaei, M. R. (2019): Molecular and physiological control of adventitious rooting in cuttings: phytohormone action meets resource allocation. - Annals of Botany 123: 929-49.

[11] El-Sayed, M. M., Abdel-Hameed, E. S., Ahmed, W. S., El-Wakil, E. A. (2008): Nonphenolic antioxidant compounds from Buddleja asiatica. - Z Naturforsch C J Biosci. 63: 483-491.

[12] Fogaca, C. M., Fett-Neto, A. G. (2005): Role of auxin and its modulators in the adventitious rooting of Eucalyptus species differing in recalcitrance. - Plant Growth Regulation 45: 1-10.

[13] Haile, G., Gebrehiwot, K., Lemenih, M., Bongers, F. (2011): Time of collection and cutting sizes affect vegetative propagation of Boswellia papyrifera (Del.) Hochst through leafless branch cuttings. - Journal of Arid Environments 75: 873-877.

[14] Hussain, I., Assis, A. M., Yamamoto, L. Y., Koyama, R., Roberto, S. R. (2014): Indole butyric acid and substrates influence on multiplication of blackberry 'Xavante'. - Ciência Rural, Santa Maria 44: 1761-1765.

[15] IUCN (2016): The IUCN Red List of Threatened Species. Red List Version 2016-2. International Union for Conservation of Nature and Natural Resources (IUCN), Gland. Retrieved on 8 Sept 2016.

[16] Justamante, M. S., Acosta-Motos, J. R., Cano, A., Villanova, J., Birlanga, V., Albacete, A., Cano, E. Á., Acosta, M., Pérez-Pérez, J. M. (2019): Integration of phenotype and hormone data during adventitious rooting in carnation (Dianthus caryophyllus L) stem cuttings. - Plants 8: 1-19.

[17] Klein, J. D., Cohen, S., Hebbe, Y. (2000): Seasonal variation in rooting ability of myrtle (Myrtus communis L) cuttings. - Scientia Horticulturae 83: 71-76.

[18] Larchevêque, M., Ballini, C., Korboulewsky, N., Montes, N. (2006): The use of compost in afforestation of Mediterranean areas: effects on soil properties and young tree seedlings. - Science of the Total Environ 369: 220-230.

[19] Ling, W. X., Zhong, Z. (2012): Seasonal variation in rooting of the cuttings from Tetraploid Locust in relation to nutrients and endogenous plant hormones of the shoot. Turkish Journal of Agriculture and Forestry 36: 257-266.

[20] Mañas, P., Castro, E., Heras, J. D. L. (2009): Quality of maritime pine (P. pinaster Ait) seedlings using waste materials as nursery growing media. - New Forest 37: 295-311.

[21] Martinez, F., Cuevas, G., Calvo, R., Walter, I. (2003): Biowaste effects on soil and native plants in semiarid ecosystem. - J Environ Qual 32: 472-479.

[22] Mewar, D., Naithani, D. C. (2016): Effect of different IBA concentrations and planting time on stem cuttings of wild pig Ficus palmate (Forsk). - Plant Archives 16: 959-962.

[23] Miller, W. P., Miller, D. M. (1987): A micropipette method for soil mechanical analysis. - Communication in Soil Science and Plant Analysis 18: 1-1.5. 
[24] Mohamedkassm, N., Fessehaye, N., Mebrahtu, D., Teaghes, K., Fessehaye, Y. (2013): The ethno-botanic significance and antimicrobial activities of two plant extracts used in Eritrea. - American Journal of Phytomedicine and Clinical Therapeutics 1(7): 520-529.

[25] Mohammed, N., Abdulwuhab, M., Mohammed, F. (2016): Antimalarial activity of crude extract of Buddleja Figure Fresen (Buddlejacea) against Plasmodium berghei in mice. Journal of Pharmacy and Biological Sciences 11(5): 27-35.

[26] Moreno-Peñaranda, R., Lloret, F., Alcañiz, J. M. (2004): Effects of sewage sludge on plant community composition in restored limestone quarries. - Restoration Ecology 12(2): 290-296.

[27] Neelam, A., Ishtiaq, M. (2001): Response of Eucalyptus camaldulensis seedlings to different soil media. - Sarhad Journal of Agriculture, Peshawar 17: 75-79.

[28] Nelson, D. W., Sommers, L. E. (1982): Total Carbon, Organic Carbon, and Organic Matter. - In: Page, A. L., Miller, R. H., Keeney, D. R. (eds.) Methods of Soil Analysis. Part 2. Chemical and Microbiological Properties. 2nd Ed. ASA-SSSA Madison, WI, pp. 539-577.

[29] Ostos, J. C., Lopez-Garrido, R., Murillo, J. M., Lopez, R. (2008): Substitution of peat for municipal solid waste- and sewage sludge-based composts in nursery growing media: effects on growth and nutrition of the native shrub Pistacia lentiscus L. - Bioresource Technology 99(6): 1793-1800.

[30] Pop, T., Pamfil, D., Bellini, C. (2011): Auxin control in the formation of adventitious roots. - Notulae Botanicae Horti Agrobotanici Cluj Napoca 39(1): 307-316.

[31] Sağlam, A. C., Yaver, S., Başer, I., Cinkiliç, L. (2014): The effects of different hormones and their concentrations on rooting of stem cuttings in Anatolian sage (Salvia fruticosa Mill.). - APCBEE Procedia 8: 348-353.

[32] Salmi, M. S., Hesami, M. (2016): Time of collection, cutting ages, auxin types and concentrations influence rooting Ficus religiosa L stem cuttings. - Journal of Applied Environmental and Biological Sciences 6(1): 124-132.

[33] Sardoei, A. S., Sarhadi, H., Rahbarian, P., Yazdi, M. R., Arbabi, M., Jahantigh, M. (2013): Effect of plant growth regulators on rooting of henna (Lawsonia inermis L). International Journal of Advanced Biological and Biomedical Research 1(11): 14661470.

[34] Sevik, H., Guney, K. (2013): Effects of IAA, IBA, NAA, and GA3 on Rooting and Morphological Features of Melissa officinalis L. Stem Cuttings. - Scientific World Journal. https://doi.org/10.1155/2013/909507.

[35] Shekhawat, M. S., Manokari, M. (2016): Impact of auxins on vegetative propagation through stem cuttings of Couroupita guianensis Aubl.: a conservation approach. https://doi.org/10.1155/2016/6587571.

[36] Siddiqui, M. I., Hussain, S. A. (2007): Effect of IBA and types of cutting on root initiation on Ficus hawaii. - Sarhad J Agri 23: 919-925.

[37] Singh, K. K., Rawat, J. M. S., Tomar, Y. K. (2011): Influence of IBA on rooting potential of torch glory Bougainvillea glabra during winter season. - J Hortic Sci Ornam Plants 3: $162-5$.

[38] Soundy, P., Mpati, K. W., Du Toit, E. S. (2008): Influence of cutting position, medium, hormone and season on rooting of fever tea (Lippia javanica L) stem cuttings. - Med Aromat Plant Sci Biotechnol 2: 114-116.

[39] Stefancic, M., Stampar, F., Osterc, G. (2005): Influence of IAA and IBA on root development and quality of Prunus 'GiSelA 5' leafy cuttings. - Hort Sci 40: 2052-2055.

[40] Swamy, S. L., Puri, S., Singh, A. K. (2002): Effect of auxins (IBA and NAA) and season on rooting of juvenile and mature hardwood cuttings of Robinia pseudoacacia and Grewia optiva. - New Forest 23: 143-157. 


$$
-7405 \text { - }
$$

[41] Tchinda, N. D., Messi, H. J. C. M., Nzweundji, G., Tsabang, N., Dongmo, B., Oumar, D., Tarkang, P. A., Caver, A., Ndoumou, D. O. (2013): Improving propagation methods of Ricinodendron heudelotti from cuttings. - South Africa Journal of Botany 88: 3-9.

[42] Thakur, M., Rana, R. C., Thakur, S. (2008): Physiochemical evaluation of Terminalia chebula fruits. - Journal Non-Timber Forest Product 15: 37-42.

[43] Topacoglu, O., Sevik, H., Guney, K., Unal, C., Akkuzu, E., Sivacioglu, A. (2016): Effect of rooting hormones on the rooting capability of Ficus benjamina L. cuttings. - Sumarski List 140(1-2): 39-44.

[44] Topp, G. C., Galganov, Y. T., Ball, B. C., Carter, M. R. (1993): Soil Water Desorption Curves. - In: Carter, M. R. (ed.) Soil Sampling and Methods of Analysis. Canadian Society of Soil Science, Lewis Publishers, Boca Raton, FL, pp. 569-581. 